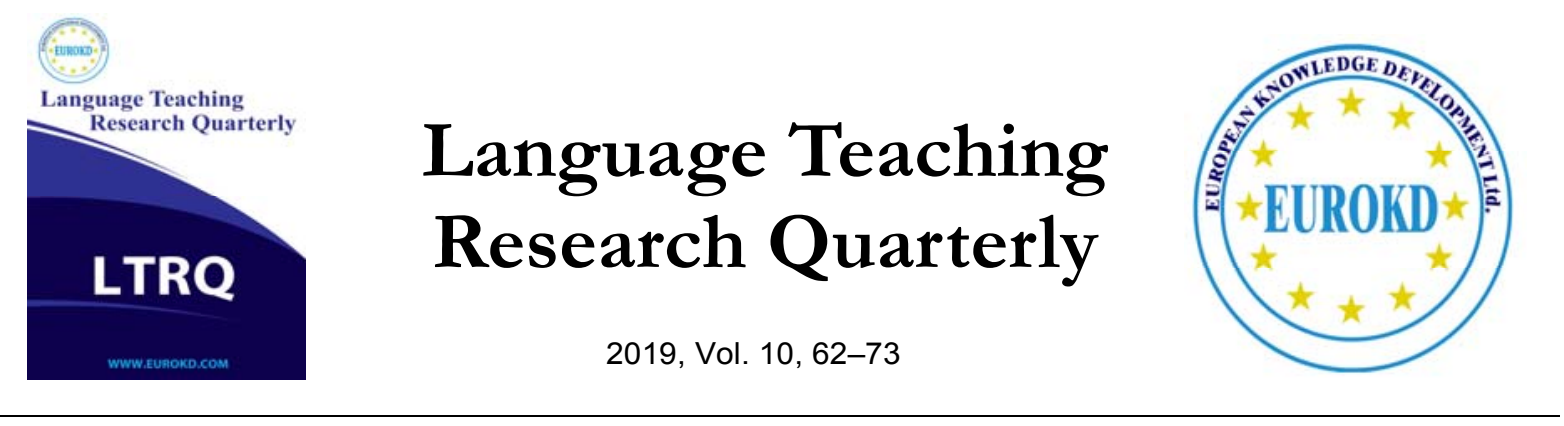

\title{
Involving Students in the Process of Teaching
}

\author{
Nastaran Eizi ${ }^{1 *}$, Faegheh Talaei ${ }^{2}$ \\ ${ }^{1}$ Taha Institute of Higher Education, Iran \\ 2 Islamic Azad University, South Tehran Branch, Iran
}

Received 11 November 2018

Accepted 28 May 2019

\begin{abstract}
Students impact on each other's learning is a topic of significance in mainstream education and various methods have been developed to measure this construct. The present study aims to develop learners' skills. Based on this paper Teacher-Centered (TC) classes are less engaging than Student-Centered (SC) classes and therefore the sense of achievement in students considerably changes, due to the level of Students' involvement in each one. To this end, 24 intermediate students (aged between 15-40) are required as well. They were divided in two different groups: one is TC and the other one is SC. Results show a significant advantage: when learners are in charge of the class_in a controlled way to prevent any possible faults_they will learn twice as much as the time instructor takes the responsibility of teaching thoroughly. The findings of this paper could lead to a better perception of students' impact in terms of students' age, interest and learning style twice as well as the time teacher impacts by considering the result of this study.
\end{abstract}

Keywords: T-Centered, S-Centered, Achievement

\section{Introduction}

English is the most popular and common language around the world. It's being used by many native or non-native speakers widely. So teaching this importance is the matter. By considering the 'history of teaching', teaching was not the thing we're doing now and it's changed a lot during years and centuries. Many researchers were struggling with these topics and methods to finally find a better way than previous ones. 
As a matter of fact, instructors used to get the class under their own control without involving students in the process of discovering. As time passed, experts investigated that involvement of learners in the process of figuring out, which happens in SC classrooms, can help the procedure of learning a lot. In line with that Brooks \& Brooks (1993) stated: "Students learn more by experiences and active involvement than by observing". So what if we involve students in the process of teaching? We've simply found out if the students are in charge of handling some parts of teaching under teacher's supervision, they'll understand the value and importance of what they realize and learn. According to H. Mcllveen (1997) learners can recognize good and bad presentations performed by the other learners and as a result they can realize whether they are friends, as an instructor or a presenter, is making a mistake.Having students involved in the process of teaching has not only been examined in the teaching and presentation form, but also it was proved thatinvolving students as partners in providing formative feedback in time for students to modify their own thinking or behavior to improve learning is a key strategy to enhance the teaching and learning process.(Fluckiger, J., Vigil, Y. T. Y., Pasco, R.,\& Danielson, K., 2010)

Here, we can give this opportunity to those shy or passive learners who cannot interact easily, no matter with teacher or classmates, to have something important to say, feeling less anxious when speaking in front of others, and being less nervous about saying something silly. It also helps not only shy students but also active ones to improve their skills, test or check their information at the right time, and recognize each other's weaknesses as well and then to feel important and more confident.

\section{Literature Review}

Persuading learners to participate in class activities has always been the topic of many papers. Getting students to take the teacher's role is a very good opportunity for both teacher and students to evaluate students' learning and production. Teacher's speaking needs to be as little as possible and instead students' role becomes more and more highlighted. It's useful for speaking, and also for learning grammar. This method leads to a situation in which the L1 is not used.

The findings demonstrate many of the benefits of e-portfolio practice regarding learners' increased sense of ownership, teacher and peer feedback, enriched learning experience at both individual and technological levels, enhanced opportunity for self-improvement and increased awareness of the learning process. Despite many positive aspects of e-portfolios use, the study reveals some challenges facing students, teachers and support staff, mainly connected with technical problems and Internet access, and the necessity for teachers and learners to change their roles to become more independent in the learning process. (Ivanova O. V., 2017).In the early part of the twentieth century, education focused on the acquisition of literacy skills: simple reading, writing, and calculating. It was not the general rule for educational systems to train people to think and read critically, to express themselves clearly and persuasively, to solve complex problems in science and mathematics. Now, at the end of the century, these aspects of 
high literacy are required of almost everyone in order to successfully negotiate the complexities of contemporary life.

As Lasagabaster (2010) expressed, motivation is a complex psychological construct regarded as one of the determinant factors in successful foreign language learning, which is why it regularly comes to the fore when trying to explain individual differences among language learners. In fact, one of the main objectives of many foreign language teachers in classrooms the world over is to increase student motivation, so that pupils may acquire a good command of English, the current main lingua franca. While many studies have been devoted to the role played by different orientations in this process, this paper focuses on the effect of the approach used in the foreign language classroom. Thus, attention is paid to the relationship between motivation and the language proficiency attained through two different approaches: Content and Language Integrated Learning (CLIL) and English as a Foreign Language (EFL).

It has been also said that the basic idea of the learner centered teaching method is that some traditional functions of the teacher are assigned to the pupils who are asked to teach the new content to their classmates by themselves. Thus, "they themselves are responsible for the quality" of their lessons. Having students involved in the process of teaching has been examined in different forms so far. As studied showed the resulting benefits of improved instruction, enhanced student learning, and better student products are worth the time and effort and contribute to a productive classroom climate where the focus is on learning more than on grading. Formative feedback involving students as partners is a key strategy to enhance the teaching and learning process (Fluckiger, J., Vigil, Y. T. Y., Pasco, R., \& Danielson, K., 2010).

On the other hand, we have to consider the role of teacher's supervision. The student's feeling of freedom is important, but it is not always increased by non-directive methods, since in some situations these may contribute to confusion and even to frustration. (McKeachie, W. J., 1954).Thus the teacher's supervision is one the most important and sensitive parts of such situation that should be taken into account along with providing a free atmosphere for the students.

In this study, both of these two methods were distinctly applied to the process to prove the fact that students' roles can considerably be influential in the learning procedure. Involving shy students in class activities by using some techniques can help them cope with shyness and any other possible problems. It is really necessary to involve passive learners in teaching and class activities. However, active students most of the time are not confident enough to teach in the class in front of others. Wang (2010) examined the use of communicative language games for teaching and learning English in Taiwanese elementary schools. In our study, students ran all parts of freer practice under teacher's supervision which was a game to learn and enjoy together.

We can clearly see the good results of having students in pair/group works (PW/GW) in the class through observations, test results or just Students' facial expressions to make more student(s)-student(s) interactions $(\mathrm{S}(\mathrm{s})-\mathrm{S}(\mathrm{s})$ interactions) rather than teacher-student(s) interactions (T-S(s) interactions) (Communicative Language Teaching, 1985 up to now). In this 
paper, we are going to evaluate learning in T-centered classes and S-centered classes in different ways.

\section{Method}

In this study, the students were challenged by Ss-Ss interactions, self/peer error corrections, and activities. In other words, they were not just in charge of taking teaching part under control. 24 female intermediate students (aged between 15-40) were divided into 2 different groups. Each group included 12 students who were taught in 2 different ways by different instructors. Sections tested the differences between familiar topics with new topics.

\section{Section 1}

\section{Phase I}

In this part, a 120-minute class was held to estimate this matter. The grammar of that session was relative clauses (defining and non-defining). It was the first time for these students to learn this topic. At first, the teacher had the students to take a pre-test in about 10 minutes. Then the teacher started to set a short context to make what she wanted to say clear. At this time, defining relative clause was taught (first L2 and then L1 for clarification as well) and they were ready to go through controlled and free practice.Before starting free practice, controlled practice was needed based on Teaching the Spoken Language: An Approach Based on The Analysis of Conversational English (Brown, Yule, 1983). For controlled practice, Ss were supposed to rewrite the sentences on the board to make relative clause in pairs which sentences were based on Oxford English Grammar Course (Swan \& Walter, 2011). Learners can struggle with the target language (TL) more if they have a very hot and challenging free practice. The game was modeled by the teacher to be done in 2 groups of 6 ; passive and active students were equally involved. During the game, students were using the TL, although it was not that easy for them. After error correction at the end of the game, post-test was taken in 10 minutes. They had a short break here to get ready for the next phase.

\section{Phase II}

While the students were taking a break, 2 students (2Ss) (one passive and one active) were voluntarily chosen to take part in the teaching section. They were both given a handout included grammar summary, explanations and examples. After break, pre-test was taken in 10 minutes by all the learners and then the 2Ss taught the grammar together. They tried to do what their teacher did and continued the previous context to clarify non-defining relative clause. The Ss-Ss, S-S and S-Ss interactions were highly seen during the session. The teacher's observation was being done all the time and she took action where necessary. Asking and answering, sharing ideas and sometimes discussing the topic was clearly seen. So they could find their weaknesses during the teaching.

It was so helpful for both groups; the students who were listening to learn and those who were teaching because students even the shy ones, who were listening, could say they were 
wrong when they were saying something incorrectly. After finishing teaching part, the controlled practice was given to students by the 2Ss as well as phase I based on Oxford English Grammar Course (Swan \& Walter, 2011). The 2Ss monitored the other students and helped them under the teacher's supervision. In this part, the students were trying so hard to make as fewer mistakes as possible in order not to be corrected by the 2Ss and the 2Ss were doing really well in order not to be mistaken as teachers.

After that, the teacher had the students be in 2 groups and for each group, set a teacher. They were supposed to make as many relative clauses as they could, according to the things which their teacher was about to say. A group with more correct sentences was going to be the winner. All the students were told to point out any errors they heard and then correct them. The teacher was listening and taking notes of any errors they were not aware of and made. At the end, posttest was taken in 10 minutes by all of the students. The result is indicated below. (figure 1 and table 1)

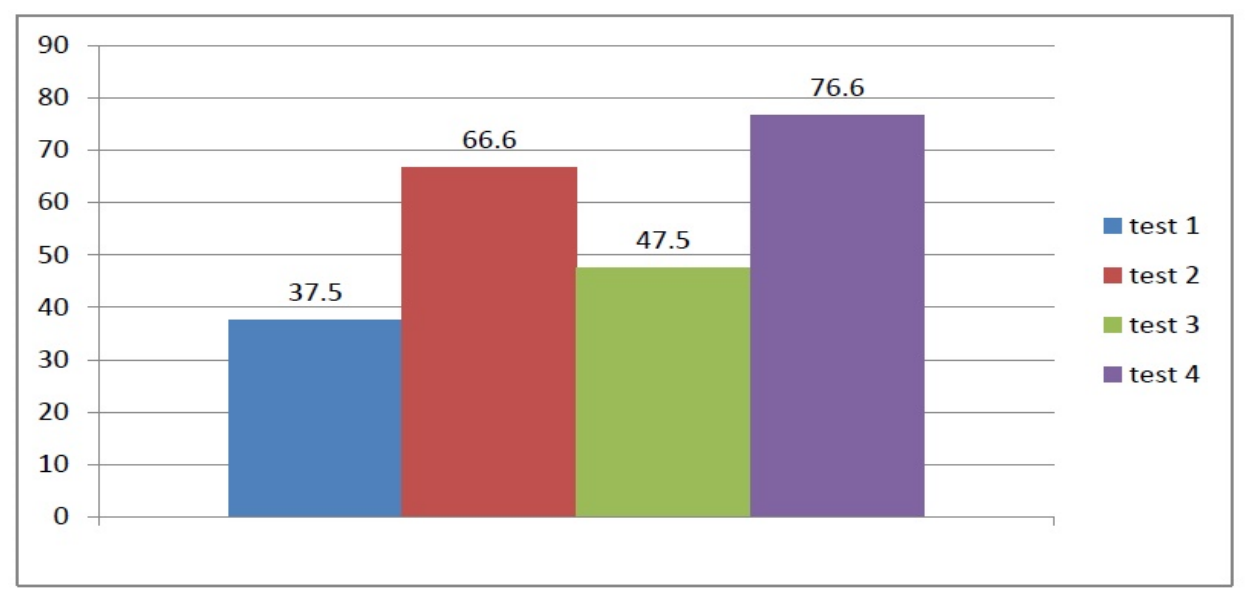

Figure 1. The results of section 1 showing students' effect on each other's learning.

Table 1

The results of Section 1

\begin{tabular}{lllll}
\hline Section 1 & Pre-test1 & Post-test1 & Pre-test2 & Post-test2 \\
\hline Student1 & $30 \%$ & $60 \%$ & $60 \%$ & $90 \%$ \\
Student2 & $50 \%$ & $70 \%$ & $50 \%$ & $80 \%$ \\
Student3 & $20 \%$ & $50 \%$ & $50 \%$ & $80 \%$ \\
Student4 & $30 \%$ & $80 \%$ & $60 \%$ & $80 \%$ \\
Student5 & $50 \%$ & $80 \%$ & $60 \%$ & $100 \%$ \\
Student6 & $50 \%$ & $90 \%$ & $30 \%$ & $100 \%$ \\
Student7 & $60 \%$ & $80 \%$ & $40 \%$ & $50 \%$ \\
Student8 & $60 \%$ & $70 \%$ & $40 \%$ & $70 \%$ \\
Student9 & $10 \%$ & $50 \%$ & $90 \%$ & $70 \%$ \\
Student10 & $40 \%$ & $60 \%$ & $50 \%$ & $70 \%$ \\
Student11 & $30 \%$ & $60 \%$ & $60 \%$ & $70 \%$ \\
Student12 & $20 \%$ & $50 \%$ & $50 \%$ & $80 \%$ \\
\hline
\end{tabular}




\section{Section 2}

\section{Phase I}

The first session was approximately held the same way as Phase Iin Section 1 with pre-test and post-test as well and L2 was the only language for teaching and talking in the class. This time, we had the whole session for teaching a different grammar (present perfect) which the students had learnt before through different ways, situations and controlled practices and the tests were based on Longman Advanced Learner's Grammar (Foley \& Hall, 2005). In this session, the teacher took the class under control. At the end of the class, 2 students were voluntarily chosen (passive and active) to take part in the teaching section for the next day. They were also given a handout included grammar summary, teacher's explanations and examples to be completely ready and prevent any possible faults.

\section{Phase II}

The next session was held the same as Phase 2 in Section 1. The difference in Section 2was using L2 NOT L1, in both Phase I and Phase II(Communicative Language Teaching, 1985 up to now) and again controlled practices and tests were based on Advanced Learner's Grammar (Foley \& Hall, 2005). The grammar here was present perfect continuous that was totally new to ALL of students. All methods and interactions were applied here as same as the previous section like having pre-test, context, study, controlled, free practice and post-test. The result is shown below. (figure 2 and table 2)

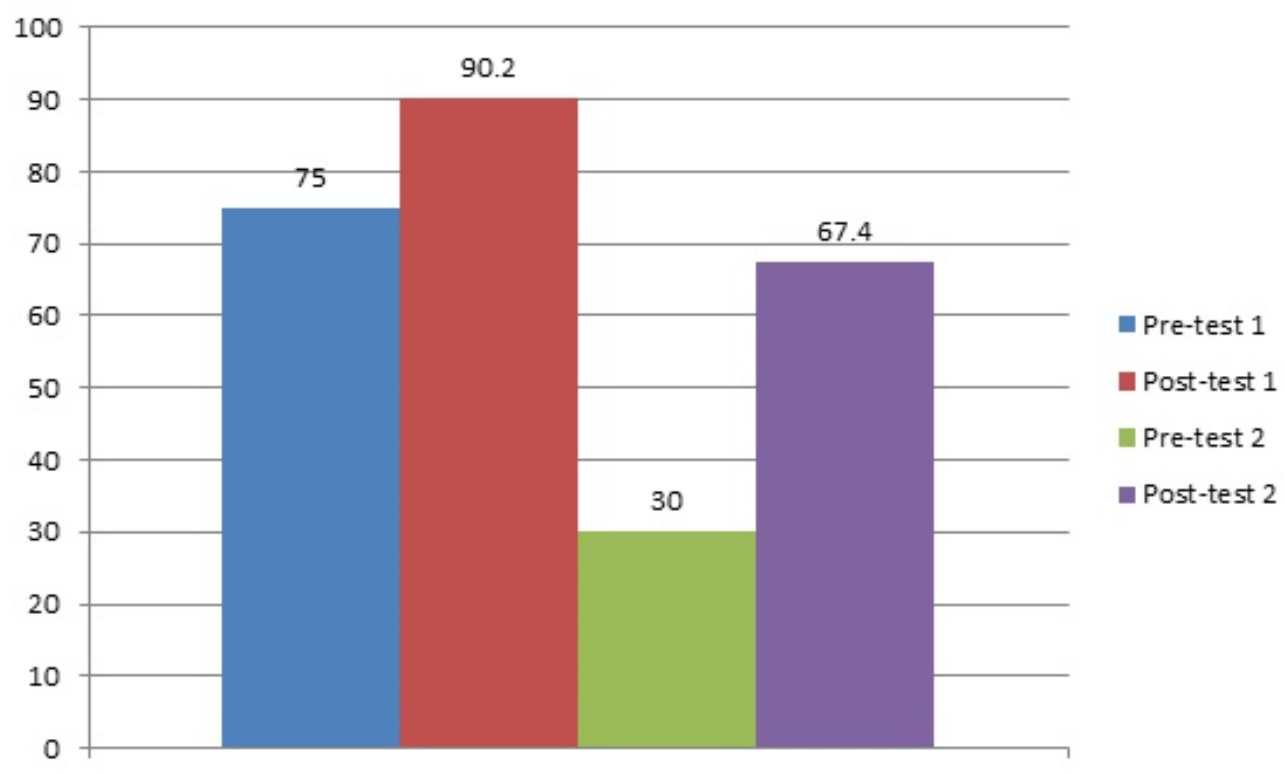

Figure 2. The results of section 2 showing students' effect on each other's learning 
Table 2

The results of Section 2

\begin{tabular}{lllll}
\hline Section 2 & Pre-test1 & Post-test1 & Pre-test2 & Post-test2 \\
\hline Student1 & $90 \%$ & $80 \%$ & $63 \%$ & $71 \%$ \\
Student2 & $60 \%$ & $86 \%$ & $72 \%$ & $78 \%$ \\
Student3 & $80 \%$ & $73 \%$ & $54 \%$ & $78 \%$ \\
Student4 & $60 \%$ & $80 \%$ & $9 \%$ & $50 \%$ \\
Student5 & $90 \%$ & $60 \%$ & $34 \%$ & $71 \%$ \\
Student6 & $40 \%$ & $66 \%$ & $36 \%$ & $78 \%$ \\
Student7 & $90 \%$ & $93 \%$ & $0 \%$ & $37 \%$ \\
Student8 & $60 \%$ & $93 \%$ & $0 \%$ & $21 \%$ \\
Student5 & $30 \%$ & $93 \%$ & $9 \%$ & $71 \%$ \\
Student10 & $70 \%$ & $80 \%$ & $18 \%$ & $71 \%$ \\
Student11 & $70 \%$ & $93 \%$ & $36 \%$ & $71 \%$ \\
Student12 & $80 \%$ & $93 \%$ & $9 \%$ & $92 \%$ \\
\hline
\end{tabular}

\section{Results and Discussion}

Learner autonomy and learner responsibility are the fundamental topics in foreign language education if the learners are not aware of their responsibilities, they can never be successful in learning new things. Learners who do not know their responsibilities in their class hours can easily demolish the enthusiasm and they can give negative energy to many who intend to learn new languages (Yagcioglu, 2015).Although there are different definitions and descriptions of learner autonomy in the literature, it can be generally defined as the ability to take responsibility of one's own learning. Learner autonomy is sometimes misunderstood in a way that it can be realized without a teacher. In fact, teachers are responsible for developing autonomous learners through their roles and practices in the classroom. Little (1996) states that learners usually do not automatically take responsibility for their learning but they need teachers to help them to do that. Teachers should have other roles than just being the source of knowledge to students. By changing their traditional role to the role of an organizer or facilitator, teachers help their students to be more responsible for their own learning. (Alonazi, 2017). Although promoting learner autonomy has been considered an educational goal in several contexts, cultural and educational settings greatly affect the way teachers incorporate its principles into their teaching practices (Y1ldırım, 2012).

As Antón (2002) stated, learner $\square$ centered discourse provides opportunities for negotiation (of form, content, and classroom rules of behavior), which creates an environment favorable to L2 learning. In contrast, teacher $\square$ centered discourse is shown to provide rare opportunities for negotiation. It is obvious that Ss are much more relaxed when they talk together. Although they know and see the teacher in the class, they feel less stressed to speak and share their ideas. We should not forget that the feelings may appear differently in different classes with different learners and levels. An elementary student might not like student-centered classes because of lack of knowledge, in our case study, the level was in a situation to embrace it.

As Jones (2007) mentioned at different times in a lesson, our role may change as the lesson moves from teacher-led to student-centered and back again. We're responsible for helping students work independently, monitoring them while they're working together, and giving them 
feedback afterward. In a whole-class activity, students and the teacher interact, and students accept the authority of the teacher as their manager. When working together, students will be responsible for their own behavior and learning while the teacher walks around the classroom monitoring. At first, some students may be too dependent on us and expect to be helped, corrected, and encouraged all the time. To begin with, we can put them into groups with less teacher-dependent students, and not pair them up with equally diffident students. It may take some time before they become more independent. As students become more independent and resourceful, they'll stop thinking "I don't know the right word, soI can't say what I want to say" but rather "I don't know exactly the right words, but I'll try to find other words to say what I mean." When in doubt, they'll ask one another for ideas and vocabulary before asking the teacher. They can also help one another by using dictionaries in class and looking up words. But they'll also ask "public" questions - questions directed to the whole class - so that everyone can benefit from hearing the answers.

Based on Community Language Learning (1970-1980), students' interactions should be highly taken into account in a class. Therefore, the purpose of this study was to heighten this importance in order to maximize the possible capacity for Ss' interactions. As Satoshi Yamagata 2016) claimed, the learner-centered approach is more effective than the teacher-centered approach with regard. The learners need to involve as much as possible to feel important, learnt and engaged. However, some may want the instructor to take this responsibility all the time in terms of showing authority in the class as a teacher.

Also, Rogers (1983) emphasized that students' perceptions of the world were important, that they were relevant and appropriate. This definition therefore emphasizes the concept of students having 'choice' in their learning.

Harden and Crosby (2000) describe teacher-centered learning strategies as the focus on the teacher transmitting knowledge, from the expert to the novice. In contrast, they describe studentcentered learning as focusing on the students' learning and 'what students do to achieve this, rather than what the teacher does'. This definition emphasizes the concept of the student 'doing'.

Back then, Garrett and Shortall (2002) indicated that one hundred and three Brazilian EFL students (beginners, elementary, intermediate) completed and then evaluated different types of learning activities: teacher-fronted grammar (TFG), student-centered grammar (SCG), teacherfronted fluency (TFF) and student-centered fluency (SCF). They were asked to evaluate these in terms of affective reactions (enjoyment, anxiety) and perceived learning value, by completing 5point scales and writing reasons for their ratings. There were some significant differences among the different levels of students. Beginners saw TFG as better for learning than SCG. Intermediates saw TFG as less fun. The same groups also viewed SCF as more fun and more relaxing than TFF, though neither of them perceived any difference in learning outcomes. Elementary learners felt TFF was better for learning than SCF, but saw no difference between them when it came to enjoyment and relaxation. So we can claim that is why the learners in our case study enjoyed student-centered situation, but the consequences of this method in Beginner and Elementary levels may not be as satisfying as Intermediate levels, which is logical. It is also 
significant to give teachers a bit excitement and challenge (Copland \&Garton\& Burns, 2013), which shows not only the learners need motivation, but also the teachers might need it in some cases to feel different situations and experience innovative ways to run their classes differently in order to make the Ss more satisfied and put themselves in a challenge. What is beneficial for instructors is that having new ways in classrooms can make the class less predictable so that the Ss will not expect the teacher to repeat the same ways.

On the other hand, Little (1995) argues that while learning strategies and learner training can play an important supporting role in the development of learner autonomy, the decisive factor will always be the nature of the pedagogical dialogue; and that since learning arises from interaction and interaction is characterized by interdependence, the development of autonomy in learners presupposes the development of autonomy in teachers.

The results of Section 1 showed when learners are in charge of the class in a controlled way to prevent any possible faults_ they will learn twice as much as the time instructor takes the responsibility (Figure 1). They were trying to show off in the class and find one another's mistakes which means they had enough motivation to do that. The Ss were enthusiastic enough to participate during the process. They did not feel embarrassed, shy or tentative for participating in the process which shows how influenced, motivated, inspired and impressed they were.

The same result was obtained once again based on the data gathered from Section 2. Although the general result of post-test 2 is not as high as post-test 1 (figure2), it can be clearly seen in figure 4 since the grammatical structure taught in section 2 did not have the same level of difficulty as section 1, 29.1\% improvement in phase I(Section 1) is the same as phase II (Section 1) but we shouldnot forget that figure 2 is showing the rising improvement percentage. Also $15.2 \%$ improvement in phase I (Section 2) is when the class was T-centered but $34 \%$ improvement in phase II (Section 2) is for the time the class is S-centered. This matter proves that even when the level of difficulty of a grammar structure changes, involving students in the process of teaching can be more effective on each one than the time teacher is in control of the class with no students' involvement in the process.

During activities they tried to help each other by saying, "Do you remember what I said? Or it is exactly what our friend mentioned." The sense of achievement was seen in the face of 2Ss who were teaching. During their teaching parts in both sections, each one was trying to say the most things and teach them herself to show her classmates how knowledgeable and talented she was and the other partner wanted to interrupt her partner and then explain some thing by completing the partner's sentences.

The way they were teaching was clearly showing the teachers' teaching methods influenced them. They kept asking their classmates if they had any questions. On the other hand, when the Ss had challenging questions, they wanted to find the best answer for them and then ask the instructor where necessary. Also the Ss were relieved and relaxed to ask their questions and get help. Moreover, the Ss as learners tried so hard to solve their classmates' problems in understanding some parts. The way they participated in the class was absolutely wonderful, fabulous and delightful. 
The results that were achieved in Section 1simulation, had rising production. It does not mean that Section 2 simulation did not have a good result, but it was not as fruitful as Section 1.It was almost acceptable since we did not use the L1 and as it has been said before, improvement was considerably better than phase 1 in Section 2 despite the fact that present perfect and present perfect continuous are always difficult to be dealt with. At the end of the session, sense of satisfaction was obviously seen in students' performance in both sections. However, we should not forget the teacher's supervision during the process.

Balasubramanian \& Shunnaq (2018) once mentioned in a study that older approaches typically involved teacher frontedness or centeredness and the learners' role was more passive. This eventually evolved into a more student $\square$ centered approach in which learners take a more active role in the language learning process. In recent years, student $\square$ centered learning has been regarded favorably. However, because of the role English currently plays internationally, traditional distinctions such as native and non $\square$ native and ESL and EFL have been blurred. English today is taught as an international language (EIL) and discussions about the best approach to teach English have pointed to the need to combine aspects of teacher frontedness and learner centeredness.

The comparison between section 1 and 2 is clearly seen below (Figure 3):

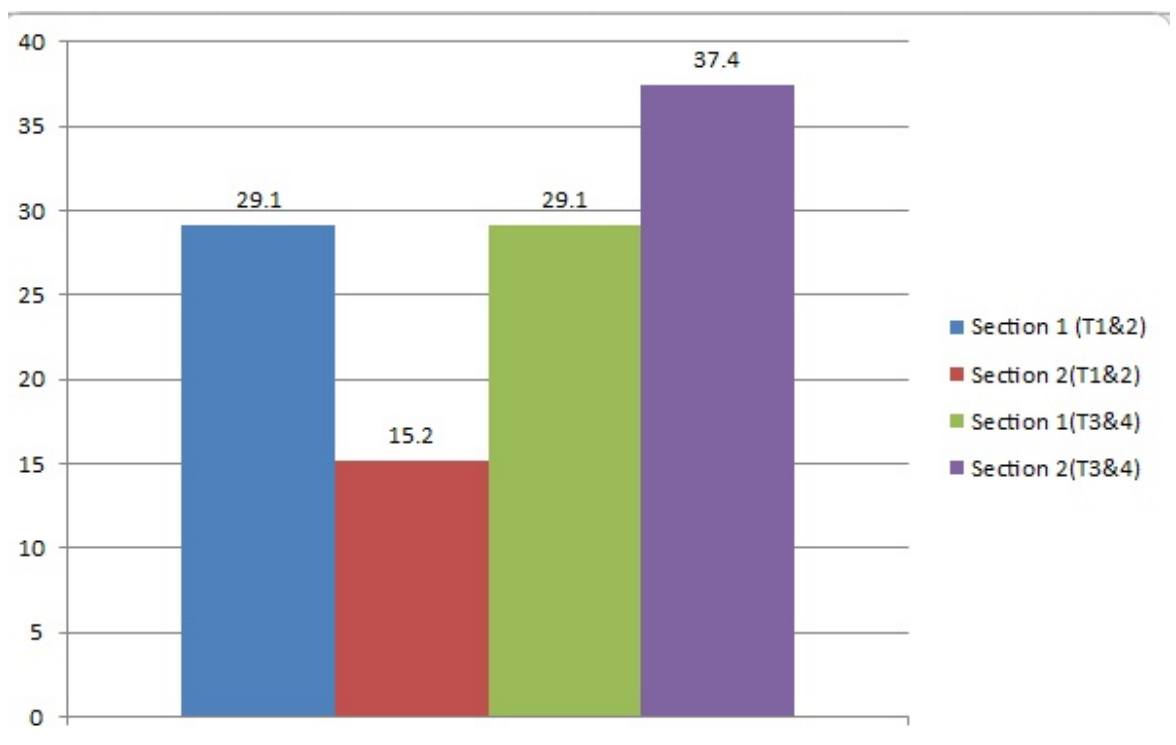

Figure 3. A comparison between section 1 and section 2

\section{Conclusion}

It has been said that when learners are involved in the process of learning, they will have better production (Mcllveen, 1997). Since teaching has this potential to make students understood better, it can be said that involving students in the process of teaching is a practical way to get better learning quality. According to our investigations, when students are involved, they try to do their best and each one of them wants to find something wrong in one another's speaking in 
this rivalry. The learners listen to their classmates who are in charge of teaching. It is not because they like to listen to anyone except their teacher, but for showing their skills and having something important to say, they do it. Also they like to find mistakes in those students who are teaching in the class in order to stand out in a crowd. Consequently, they will have fewer errors and their abilities will be enhanced to find mistakes much better than before.

In both mentioned classes, students made progress in different ways on account of slight changes applied to section 1 and 2 such as: using L1 and level of difficulty of the grammars taught. Considering these differences, we should pay attention to the other factors that may be of an effect in the results, say students' feelings, desire to be seen and etc. (e.g.: student 7 in Table1). Injecting excitement to the classes can result different things such as motivation, concentration, confidence and awareness for all learners. All in all, it's a given opportunity for those who want to shine in the class and be more assertive. The better they feel, the better they'll produce and learning will happen easily. Taking everything into account, it's obvious that having students' involvement in all parts of a class, even the teaching part, works out and can have better production, not only for active or good students, but also for shy or weak students.

\section{References}

McIlveen, H., Greenan, K., \& Humphreys, P. (1997). Involving students in teaching and learning: a necessary evil? Quality Assurance in Education,5(4) 231-238.

Brown, G., \& Yule, G. (1983). Teaching the Spoken Language: An Approach Based on the Analysis of Conversational English, Cambridge: Cambridge University Press.

Wang, Y. H. (2010). Using communicative language games in teaching and learning English in Taiwanese primary schools. Journal of Engineering Technology and Education, 7(1), 126-142.

Swan, M.,\& Walter, C. (2011). Oxford English grammar course advanced, Oxford: Oxford university press.

Brooks, J. G., \& Brooks, M. G. (1993). In search of understanding: The case for constructivist classrooms. Alexandria, VA: Association of Supervision and Curriculum Development.

Foley, M.,\& Hall, D. (2005). Advanced Learner's Grammar, England: Longman.

Bransford, J.D. (2000). How people learn: Brain, mind, experience, and school, Washington, DC: National Academy Press.

Ivanova, O.V. (2017). The use of e-portfolio to develop English language learners' autonomy and independence. Information Technologies and Learning Tools, 60(4),155-165.

Fluckiger, J., Vigil, Y. T. Y., Pasco, R., \& Danielson, K. (2010). Formative feedback: Involving students as partners in assessment to enhance learning. College teaching, 58(4), 136-140.

McKeachie, W. J. (1954). Student-centered versus instructor-centered instruction.Journal of Educational Psychology, 45(3), 143-150.

Lasagabaster, D. (2010). English achievement and student motivation in CLIL and EFL settings. Innovation in Language Learning and Teaching, 5(1),3-18.

Fluckiger, J.,Vigil, Y. T. Y., Pasco, R., \& Danielson, K. (2010). Formative feedback: Involving students as partners in assessment to enhance learning. College Teaching, 58(4), 136-140

Yamagata, S. (2016). Comparing core-image-based basic verb learning in an EFL junior high school: Learnercentered and teacher-centered approaches. Language Teaching Research, 22(1), 65-93. 
Peter Garrett, P.,\& Shortall, T.(2002). Learners' evaluations of teacher-fronted and student-centered classroom activities. Language Teaching Research, 6(1), 25-57.

Copland, F.,Garton, S., \& Burns, A.(2013). Challenges in Teaching English to Young Learners: Global Perspectives and Local Realities. TESOL Quarterly, 48(4), 738-762.

Balasubramanian, C., \& Shunnaq, S. R. (2018). Teacher $\square$ Fronted Classes. The TESOL Encyclopedia of English Language Teaching.

Yagcioglu, O. (2015). New approaches on learner autonomy in language learning. Procedia-Social and Behavioral Sciences, 199, 428-435.

Alonazi, S. M. (2017). The Role of Teachers in Promoting Learner Autonomy in Secondary Schools in Saudi Arabia. English Language Teaching, 10(7), 183-202.

Little, D. (1996). Freedom to learn and compulsion to interact: promoting learner autonomy through the use of information systems and information technologies. Taking control: Autonomy in language learning,7(8), 203218.

Yildirim, O. (2012). A Study on a Group of Indian English as a Second Language Learners' Perceptions of Autonomous Learning. Online Submission, 3(2), 18-29.

Antón, M. (2002). The discourse of a learner-centered classroom: Sociocultural perspectives on teacher-learner interaction in the second-language classroom. The Modern Language Journal, 83(3), 303-474.

Harden, R.M., \& Crosby, J. (2000). AMEE Guide No 20: The good teacher ismore than a lecturerthe twelve roles of the teacher. Medical Teacher, 22(4), 334-347.

Burnard, P. (1999). Carl Rogers and postmodernism: Challenged in nursing and health sciences. Nursing and Health Sciences, 1(4), 241-247.

Jones, L. (2007). The student-centered classroom, The USA: Cambridge university press.

Wohlfarth, D., Sheras, D., Bennett, J. L., Simon, B., Pimentel, J. H., \& Gabel, L. E. (2008). Student Perceptions of Learner-Centered Teaching. Insight: A Journal of Scholarly Teaching, 3, 67-74.

Little, D. (1995). Learning as dialogue: The dependence of learner autonomy on teacher autonomy. System, 23(2), 175-181. 